\title{
Oscillatory Bromate-Oxalic Acid-Ce-Acetone-Sulfuric Acid Reaction, in CSTR
}

\author{
Janaina A. M. Pereira and Roberto B. Faria* \\ Instituto de Química, Universidade Federal do Rio de Janeiro, CP 68563, Rio de Janeiro 21945-970, Brazil
}

\begin{abstract}
São relatadas, pela primeira vez, a observação de oscilações periódicas, em reator agitado de fluxo contínuo (CSTR), para o sistema bromato-ácido oxálico-Ce(IV)-acetona-ácido sulfúrico. Identificou-se que a reação entre $\mathrm{Ce}(\mathrm{IV})$ e a acetona, até então não descrita na literatura e que ocorre antes dos reagentes serem adicionados ao reator, é um fator decisivo para o aparecimento de oscilações regulares.
\end{abstract}

Periodic oscillations were observed for the first time, in a CSTR, in the system bromate-oxalic acid-Ce(IV)-acetone-sulfuric acid, in a CSTR. A reaction between Ce(IV) and acetone, until now not described in the literature and occurring before the addition of the reagents to the reactor, was identified as a decisive factor for the appearing of the regular oscillations.

Keywords: oscillating reaction, bromate, oxalic acid, cerium(IV)-acetone reaction

\section{Introduction}

The bromate-oxalic acid-cerium-sulfuric acid reaction is one of the Belousov-Zhabotinsky (BZ) ${ }^{1,2}$ type oscillators. The oscillatory behaviour of the title system has been observed, under batch conditions, when an inert gas is bubbled or when acetone is used to remove the bromine produced during the reaction course. Noszticzius and Bódiss $^{3}$ reported oscillations in the system consisting only of $\mathrm{BrO}_{3}^{-}$, oxalic acid, cerium ion and $\mathrm{H}_{2} \mathrm{SO}_{4}$, when $\mathrm{H}_{2}$ was bubbled through the reaction mixture. Ševčík and Adamčíková ${ }^{4}$ observed periodic oscillations in the system catalyzed by cerium or manganese, using a $\mathrm{N}_{2}$ flow. Later, the same authors reported regular oscillations in the system with $\mathrm{Ce}(\mathrm{III})$ as catalyst and investigated the influence of the rate of flow of three inert gases $\left(\mathrm{H}_{2}, \mathrm{~N}_{2}\right.$ and $\left.\mathrm{Ar}\right)$ on the oscillation period. ${ }^{5}$ Noszticzius, Stirling and Wittmann 6 determined the "rate constant" for bromine removal, as a function of the flow rate of $\mathrm{N}_{2}$ and the reaction volume. This "rate constant" was also used as a bifurcation parameter. Noszticzius" found oscillations in the system with cerium and acetone, which were also observed by Field and Boyd. ${ }^{8}$ Ševčík and Adamčíková ${ }^{5}$ described periodic oscillations in the system with acetone, catalyzed by $\mathrm{Ce}$ (III). In the same work, ${ }^{5}$ a study of the bromate-oxalic acid-Ce(III)- $\mathrm{H}_{2} \mathrm{SO}_{4}$ reaction was carried out, using a flowthrough reactor, in which regular oscillations were

* e-mail: faria@iq.ufrj.br observed. Wittmann, Stirling and Bódiss ${ }^{9}$ investigated the effect of the variation of the acetone concentration in the system containing acetone and ceric ion, determining temporary non-oscillatory states and induction period. Berenstein, Agreda and Barragán ${ }^{10}$ studied the effect of the addition of methyl-ketones on the induction period. In addition to the Ševčík and Adamčíková's work, ${ }^{5}$ the system with acetone and catalyzed by manganese was studied by Weigt, ${ }^{11}$ Biswas et al. ${ }^{12}$ and Guedes and Faria, ${ }^{13}$ also under batch conditions. In Guedes and Faria's work, ${ }^{13}$ two characteristically different patterns of oscillations, depending on the method of mixing of the reagents and controlled by the acetone concentration, were determined.

In this work we report for the first time observation of regular oscillations for the title reaction, in CSTR. The on set of the oscillatory behaviour depends on the conversion of $\mathrm{Ce}$ (IV) to $\mathrm{Ce}$ (III), in the reagent solution, by a previously unsuspected reaction with acetone.

\section{Experimental}

The analytical-grade chemicals $\mathrm{KBrO}_{3}$ (VETEC), $\mathrm{Ce}\left(\mathrm{SO}_{4}\right)_{2} \cdot 4 \mathrm{H}_{2} \mathrm{O}$ (VETEC), oxalic acid (Riedel-de-Haën AG), $\mathrm{H}_{2} \mathrm{SO}_{4}$ (Grupo Química) and acetone (Merck) were used without further purification. Distilled water was used in all preparations. The state of the system was followed by UV-Vis spectroscopy, employing a diode array spectrophotometer (HP 8452-A) and a standard quartz cuvette (Hellma 100-QS) with an optical path length of 1 
$\mathrm{cm}$, equipped with a $3 \times 5 \mathrm{~mm}$ Teflon-coated cylindrical stirring bar. The cuvette was placed inside a jacketed cuvette holder, thermostated by a circulating bath, having a water-powered magnetic stirrer. All the experiments were carried out at $25 \pm 0.3{ }^{\circ} \mathrm{C}$.

The cuvette was converted in a flow-through reactor by the use of two syringe pumps (Cole Parmer 74900-30), each one containing three $60 \mathrm{~mL}$ plastic syringes. The syringe pumps were used to lead, alternately, three different reactant solutions into the reactor. The cuvette was closed with a rubber stopper containing five holes. Three of them were used for the PTFE 1/32" tubes which carried the reactant solutions. The fourth hole was used for a tube connected to a water aspirator pump and the fifth one remained opened to avoid a pressure change inside the cuvette.

All the experiments were initiated by the addition of $0.5 \mathrm{~mL}$ of each reagent solution to the cuvette, in the following order: Sol. A (oxalic acid), Sol. B (Ce(IV), sulfuric acid and acetone), and Sol. C (bromate). The total volume of the reaction mixture inside the cuvette during the continuous operation of the syringe pump was 1.58 $\mathrm{mL}$, from which the flow rate, $k_{0}$, was calculated. The dynamic behaviour of the system was monitored at 400 $\mathrm{nm}$ and $340 \mathrm{~nm}$.

\section{Results and Discussion}

At the beginning of the experiments, it was noticed that the use of the yellow Sol. B, due to the Ce(IV), did not allow us to observe a regular oscillatory behaviour. Only irregular low amplitude peaks were observed (Figure 1a). After several hours, when the Sol. B became totally colourless, the periodic high amplitude peaks could be observed. Figure $1 \mathrm{~b}$ presents the evolution of the behaviour of this system, with the appearance of the regular oscillations. These oscillations showed initially some irregularities close to the base line, until the transition to a pattern, without the base line irregularities (Figure 1c - last oscillation). In this way, to observe regular oscillations like that shown in Figure 2, we had to leave the Sol. B resting overnight until we had a completely colourless solution.

Using a rested overnight Sol. B, perfectly regular high amplitude oscillations were observed for acetone concentrations in the range of 0.104 to $0.128 \mathrm{~mol} \mathrm{~L}^{-1}$ and $1.42 \mathrm{~mol} \mathrm{~L}^{-1}$ sulfuric acid. The period of the oscillations had shown to be sensitive to the flow rate. There was a reduction of approximately $20 \%$ with the increase in $\mathrm{k}_{0}$ in the range of $1.19 \times 10^{-2}$ to $3.52 \times 10^{-2} \mathrm{~s}^{-1}$.

The colour change in Sol. B, containing initially $\mathrm{Ce}(\mathrm{IV})$, sulfuric acid and acetone, from yellow to

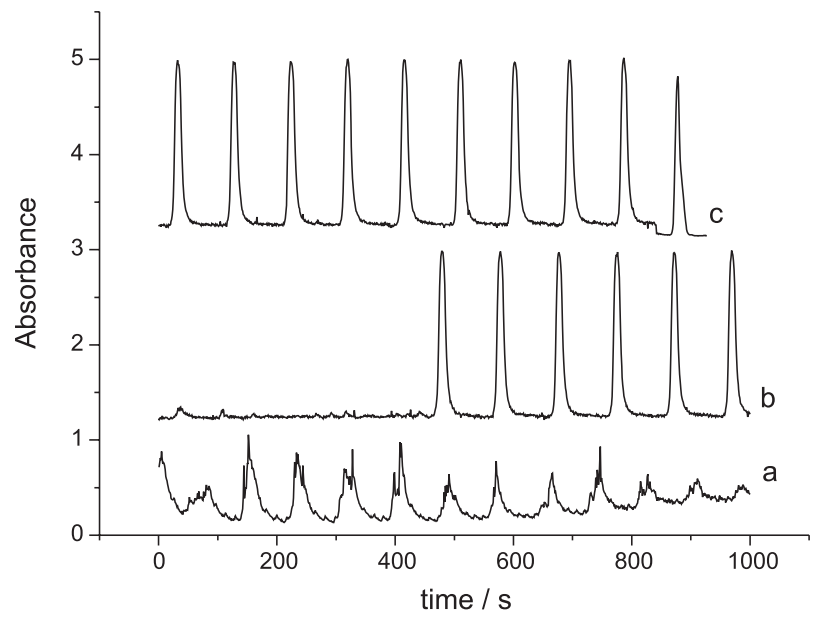

Figure 1. Time series showing the evolution of the system behaviour as the $\mathrm{Ce}(\mathrm{IV})$ turns in $\mathrm{Ce}(\mathrm{III})$ in the Sol. B. (a) irregular oscillations at the beginning of the experiment; $(b)$ appearance of regular high amplitude oscillations with irregularities in the base line, after 190 min.; (c) transition to regular oscillations without irregularities in the base line, after $210 \mathrm{~min}$ (notice the last two oscillations). Initial conditions: $\left[\mathrm{BrO}_{3}^{-}\right]_{0}=0.01 \mathrm{~mol} \mathrm{~L}^{-1}$; $[\mathrm{Ce}(\mathrm{IV})]_{0}=0.001 \mathrm{~mol} \mathrm{~L}^{-1}$; $\left[\mathrm{H}_{2} \mathrm{C}_{2} \mathrm{O}_{4}\right]_{0}=0.025 \mathrm{~mol} \mathrm{~L}^{-1} ;\left[\mathrm{CH}_{3} \mathrm{COCH}_{3}\right]=0.115 \mathrm{~mol} \mathrm{~L}^{-1} ;\left[\mathrm{H}_{2} \mathrm{SO}_{4}\right]_{0}=$ $1.42 \mathrm{~mol} \mathrm{~L}^{-1} ; \mathrm{T}=25^{\circ} \mathrm{C} ; \lambda=340 \mathrm{~nm} ; \mathrm{k}_{0}=1.19 \times 10^{-2} \mathrm{~s}^{-1}$ (curve $\left.a\right) ; \mathrm{k}_{0}$ $=2.61 \times 10^{-2} \mathrm{~s}^{-1}$ (curves $b$ and $c$ ). Ordinate data in curve $a$ were multiplied by 5 ; ordinate data in curves $b$ and $c$ were shifted by 1 and 3 , respectively.

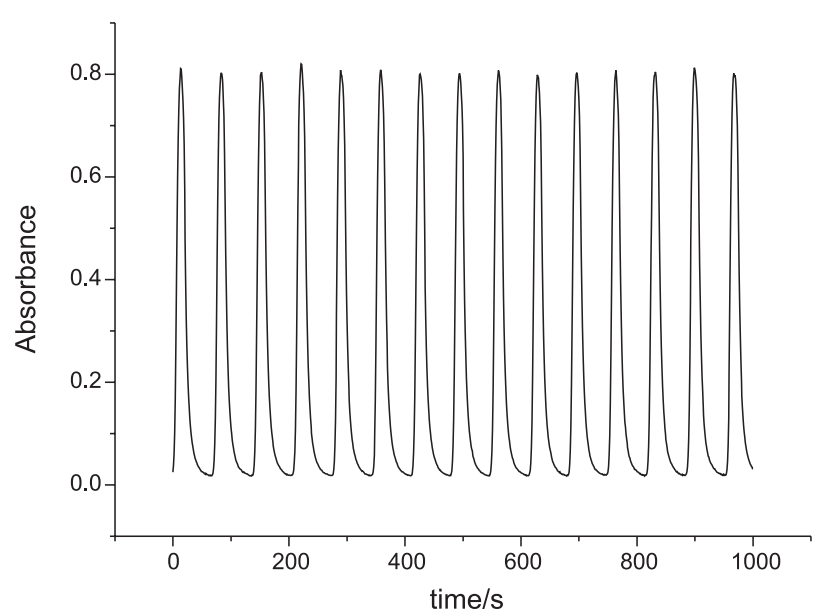

Figure 2. Regular oscillations at $\lambda=340 \mathrm{~nm}$. Initial conditions: same as in Figure 1, curves $b$ and $c$.

colourless, is a result of the reduction of $\mathrm{Ce}$ (IV) to $\mathrm{Ce}$ (III), by means of a slow reaction with acetone. Following this reaction at the $\mathrm{Ce}(\mathrm{IV})$ absorption band, it was shown that it is a slow process, first-order in Ce(IV), with an observed rate constant of $9.21 \times 10^{-6} \mathrm{~s}^{-1}$ at $[\mathrm{Ce}(\mathrm{IV})]=0.001 \mathrm{~mol} \mathrm{~L}^{-1}$, $\left[\mathrm{H}_{2} \mathrm{SO}_{4}\right]=1.26 \mathrm{~mol} \mathrm{~L}^{-1}$ and [acetone] $=0.058 \mathrm{~mol} \mathrm{~L}^{-1}$ initial concentrations.

The role of the acetone in BZ systems with oxalic acid is believed to be related to the bromine removal, necessary to bring about the oscillations. ${ }^{3-6}$ According to Ševčík and 
Adamčíková, ${ }^{5}$ it can be done by means of an inert gas bubbling, a flow-through reactor or a reaction with some additional substrate like acetone. As all the experiments with this system were carried out with an excess of acetone, the role of this substrate in withdrawing bromine cannot be discarded. However, in addition to the chemical removal of bromine which occur inside the reactor and in the time scale of the oscillation kinetics, the reaction between $\mathrm{Ce}(\mathrm{IV})$ and acetone in the feeding reactant solution, changing most of the $\mathrm{Ce}(\mathrm{IV})$ to $\mathrm{Ce}(\mathrm{III})$, was a crucial factor for the development of a regular oscillatory behavior in a CSTR. We conclude that with only Ce(IV) the system does not oscillate in a regular mode. To obtain regular oscillations it is necessary to attain a minimum [Ce(III)]/ [Ce(IV)] ratio which can be obtained only after the very slow reaction between $\mathrm{Ce}(\mathrm{IV})$ and acetone had produced some $\mathrm{Ce}(\mathrm{III})$.

\section{Acknowledgments}

This work was sponsored by CAPES and CNPq.

\section{References}

1. Belousov, B.P.; Sb. Ref. Rad. Medizinar. 1959, 145.

2. Zhabotinsky, A. M.; Dokl. Akad. Nauk. SSSR 1964, 175, 392.

3. Noszticzius, Z.; Bódiss, J.; J. Am. Chem. Soc. 1979, 101, 3177.

4. Ševčík, P.; Adamčíková, L.; Collect. Czech. Chem. Commun. 1982, 47, 891.

5. Ševčík, P.; Adamčíková, L.; Collect. Czech. Chem. Commun. 1985, 50, 799.

6. Noszticzius, Z.; Stirling, P.; Wittmann, M.; J. Phys. Chem. 1985, 89, 4914.

7. Noszticzius, Z.; Magy. Kem. Foly. 1979, 85, 330.

8. Field, R. J.; Boyd, P. M.; J. Phys. Chem. 1985, 89, 3707.

9. Wittmann, M.; Stirling. P.; Bódiss, J.; Chem. Phys. Lett. 1987, 141, 241.

10. Berenstein, I.; Agreda, J.; Barragán, D.; Phys. Chem. Chem. Phys. 1999, 1, 4601.

11. Weigt,H. R.; Z. Chem. 1990, 30, 260.

12. Biswas, S.; Mukherjee, K.; Mukherjee, D. C.; Moulik, S. P.; J. Phys. Chem. A. 2001, 105, 8857.

13. Guedes, M. C.; Faria, R. B.; J. Phys. Chem. A. 1998, 102, 1973. 